\title{
Mitral Restenosis in the Early Postoperative Period of a Patient with Systemic Lupus Erythematosus
}

\author{
Pablo Maria Alberto Pomerantzeff, Jeanne D'Arc Honória Corrêa, Carlos Manuel de Almeida Brandão, \\ Raimunda Violante Campos de Assis, Adib Domingos Jatene
}

\author{
São Paulo, SP - Brazil
}

\begin{abstract}
A forty eight year old woman, who had undergone mitral comissurotomy and subsequently developed early restenosis, presented with major comissural fusion and verrucous lesions on the cuspid edges of the mitral valve, with normal subvalvar apparatus. Patient did well for the first six months after surgery when she began to present dyspnea on light exertion. A clinical diagnosis of restenosis was made, which was confirmed by an echocardiogram and cardiac catheterization. She underwent surgery, and a stenotic mitral valve with verrucous lesions suggesting Libman-Sacks' endocarditis was found. Because the diagnosis of systemic lupus erythematosus (SLE) had not been confirmed at that time, a bovine pericardium bioprosthesis (FISICS-INCOR) was implanted. The patient did well in the late follow-up and is now in NYHA Class I.
\end{abstract}

Systemic lupus erythematosus (SLE) is a disease that often has cardiac manifestations, such as valvar lesions, pericardial thickening and effusion, and heart failure due to myocarditis.

This is the report of a patient with mitral stenosis, who had undergone mitral comissurotomy, after which restenosis quickly occurred resulting in the need of mitral valve replacement.

\section{Case report}

The patient is a forty eight year old woman, who had progressive dyspnea on exertion for the last two years ago (NYHA Class III) and who had episode of acute pulmonary edema six months earlier. She was on furosemide and potassium chloride. When she was admitted to the hospital, she was well oriented, acyanotic, anicteric and dyspneic; on physical exam she weighted $75.6 \mathrm{~kg}$ and was $1.55 \mathrm{~m}$ tall, her blood pressure was $130 / 90 \mathrm{mmHgc}$ and her heart rate was $90 \mathrm{bpm}$. Her apical impulse was not visible and S1 and a diastolic thrill could be palpable. On auscultation, a diastolic rumble III/IV could be heard. Left atrial enlarge-

São Paulo, SP - Brazil

Instituto do Coração do Hospital das Clínicas - FMUSP

Mailing address: Pablo M. A. Pomerantzeff - Incor - Av. Dr. Enéas C. Aguiar, 44 05403-000 - São Paulo, SP - Brazil ment was revealed on the electrocardiogram and the Dopplerechocardiogram showed severe mitral stenosis, with 1.3 $\mathrm{cm}^{2}$ mitral valve area and a $33 \mathrm{mmHg}$ peak transvalvar gradient. Ejection fraction was $71 \%$ and left atrium diameter $4.6 \mathrm{~cm}$. Cardiac catheterization showed moderate mitral stenosis, with left ventricular end diastolic pressure (LVEDP) of $10 \mathrm{mmHg}$ and pulmonary wedge pressure (PWP) of $22 \mathrm{mmHg}$. The patient had had bone marrow aplasia one year ago, anemia and thrombocytopenia, with 92,000 platelets and lupic anticoagulant was negative.

Patient underwent mitral comissurotomy in 3/1992, and the mitral valve had severe comissural fusion, verrucuous lesions on the cuspid edges and normal subvalvar apparatus (fig. 1). She did well early in the postoperative period. Platelet count fell down to 52,000 and she needed transfusion of 5 platelet units on the $5^{\text {th }}$ postoperative day. Steroids were started on the $4^{\text {th }}$ day PO due to thrombocytopenia.

She did well for six months, when she began to present dyspnea on light exertion. An echocardiogram was performed and showed moderate mitral stenosis, with comissural fusion and cuspid thickening. At cardiac catheterization, moderate mitral stenosis and regurgitation were diagnosed, with LVEDP and PWP values of $17 \mathrm{mmHg}$ and $31 \mathrm{mmHg}$, respectively. After surgery, the patient was placed on furosemide and steroids. On September 24, 1992, the lupic anticoagulant was present.

She was reoperated upon in October, 1992 and a bovine pericardium bioprosthesis, model FISICS-INCOR, was implanted. The excised mitral valve showed stenosis with verrucous lesions, suggesting Libman-Sacks' endocarditis. Pathological examination of the valve showed that vegetations were constituted of fibrin, rare neutrophils and erythrocytes. The patient did well in the late follow-up and is now in NYHA class I

\section{Discussion}

There are several reports on the association of mitral valve disease and SLE ${ }^{1,2}$. In many cases, it is difficult to evaluate cardiac involvement in theses patients, because of the coexistence of other symptoms due to polyserositis, such as pericarditis, chronic renal failure, chronic pulmonary disease and nervous system diseases, among others. 


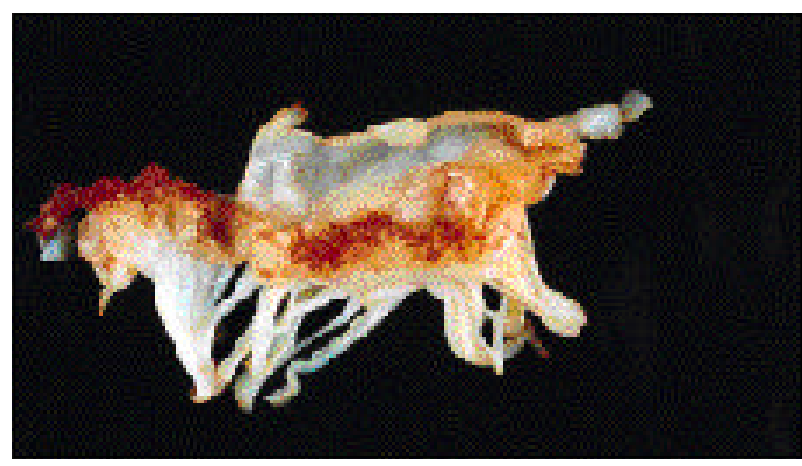

Fig. 1 - Mitral valve macroscopic aspect.

The echocardiogram can be very helpful in the diagnosis of cardiac lesions in these patients ${ }^{1,3}$.

In the present case, restenosis of the mitral valve developed quickly and valvar replacement was needed six months later. Fast evolution to restenosis can be explained by the use of steroids in these patients, or by the evolution of the inflammatory process of the disease, which results in cuspid retraction, vegetations and verrucous lesions that lead to mitral stenosis or regurgitation. Vegetation and verrucous lesions are pathognomonic of Libman-Sacks' endocarditis ${ }^{4}$ and were found in both surgeries. The pathological exam showed vegetations formed by fibrin, rare neutrophils and erythrocytes.

Some authors suggest that conservative procedures should not be performed in these cases ${ }^{2}$, due to the above reasons, as well as to the high incidence of acute renal failure of these patients in the postoperative period, which increases the risk of a reintervention ${ }^{5}$. In the present case, the patient did not have any renal complication.

Bioprostheses should be used instead of mechanical prostheses, since the risk of bleeding is greater when anticoagulants are used in association with steroids ${ }^{6}$.

\section{References}

1. Grimberg M, Rossi EG, Mansur AJ, et al. - Insuficiência mitral rapidamente progressiva no decorrer de manifestação inicial de lúpus eritematoso sistêmico. Correlação anátomo-clínico-ecocardiográfica. Arq Bras Cardiol 1985; 45: 189-92.

2. Dajee H, Hurley EJ, Szarnicki RJ - Cardiac valve replacement in systemic lupus erythematosus. A review. J. Thorac Cardiovasc Surg 1983; 85: 718-26.

3. Galve E, Candell-Riera J, Pigrau C, Miralda GP, Castilho HG, Soler J - Prevalence, morphologic types, and evolution of cardiac valvular disease in systemic lupus erythematosus. New Engl J Med 1988; 319: 817-23.
4. Libman E, Sacks B - A hitherto undescribed form of valvular and mural endocarditis. Arch Int Med 1924; 33: 701-37.

5. Straaton KV, Chatham WW, Reveille JD, Koopman WJ, Smith SH - Clinically significant valvular heart disease in systemic lupus erythematosus. Am J Med 1988; 85: 645-50.

6. Alameddine AK, Schoen FJ, Yanagi H, Couper GS, Collins JJ, Cohn LH - Aortic or mitral valve replacement in systemic lupus erythematosus. Am J Cardiol 1992; 70: $955-6$. 